\title{
Covalent Modification of Glassy Carbon Electrodes with $\beta$-Alanine for Voltammetric Separation of Dopamine and Ascorbic Acid
}

\author{
Lei Zhang, ${ }^{* \dagger}$ and Yu-Gang Sun** \\ *Department of Chemistry, University of Science and Technology of China, Hefei, Anhui, 230026, PR China \\ **Department of Chemistry, University of Washington, Seattle, WA, 98195-1700, USA
}

\begin{abstract}
$\beta$-Alanine was covalently grafted on a glassy carbon electrode (GCE) by amine cation radical formation in the electrooxidation process of the amino-containing compound. X-ray photoelectron spectroscopy (XPS) and cyclic voltammetry (CV) proved the immobilization of $\beta$-alanine monolayer on GCE. The electrode shows strong electrocatalytic functions to dopamine (DA) and ascorbic acid (AA), reducing the overpotentials by $0.20 \mathrm{~V}$ and $0.23 \mathrm{~V}$, respectively. Due to its different catalytic effects toward DA and AA, the modified electrode resolved the overlapping voltammetric responses of DA and AA into two well-defined voltammetric peaks by CV or differential pulse voltammetry (DPV), which can be used for the simultaneous determination of these species in a mixture. The catalytic peak current obtained from DPV was linearly related to DA and AA concentrations in the ranges of $4.0 \times 10^{-6}-5.0 \times 10^{-4}$ $\mathrm{mol} / \mathrm{L}$ and $2.0 \times 10^{-5}-6.0 \times 10^{-3} \mathrm{~mol} / \mathrm{L}$ with correlation coefficients of 0.997 and 0.995 , respectively. The detection limits $(3 \sigma)$ for DA and AA were $2.4 \times 10^{-6} \mathrm{~mol} / \mathrm{L}$ and $1.2 \times 10^{-5} \mathrm{~mol} / \mathrm{L}$, respectively. The electrode shows good sensitivity, selectivity and stability, and has been applied to the determination of DA and AA simultaneously in samples with satisfactory results.
\end{abstract}

(Received April 2, 2001; Accepted June 20, 2001)

\section{Introduction}

Recently, considerable effort has been excerted in the development of voltammetric methods for the determination of DA and AA in biological samples. It is known that direct redox reactions of these species at bare electrodes are irreversible and therefore require high overpotentials. ${ }^{1}$ Moreover, they can be oxidized at very similar potentials and often suffer from a pronounced fouling effect, which results in rather poor selectivity and reproducibility. The ability to determine DA and AA selectively has been a major goal of electroanalytical research. ${ }^{2}$ Since the basic concentration of DA $(<100 \mathrm{nM})$ is much smaller than that of AA $(100-500 \mu \mathrm{M})$ in biological samples, ${ }^{3}$ both sensitivity and selectivity are of equal importance in developing voltammetric procedures. Various approaches, mainly based on ion-exchange membrane-coated electrodes, have been attempted to solve the problems. ${ }^{4-17}$ Ion exchange membranes of both anionic and cationic nature have been developed to electrostatically accumulate/trap oppositely charged analyte molecules. Among them are Nafion, ${ }^{5}$ poly(ester sulfonic acid), ${ }^{6}$ poly(4-vinylpyridine),${ }^{7}$ stearate, ${ }^{8} \omega$-mercapto carboxylic acids, ${ }^{9}$ poly(monomeric eugenol), ${ }^{10}$ overoxidized poly(1-(2-carboxyethyl))pyrrole, ${ }^{11}$ 4-aminophenylacetic acid, ${ }^{12}$ clay, ${ }_{13}$ overoxidized polypyrrole,,${ }^{14,15}$ poly(indole-3-acetic acid ${ }^{16}$ and poly $\left[\mathrm{Os}(\mathrm{bpy})_{2}(\mathrm{PVP})_{10} \mathrm{Cl}\right] \mathrm{Cl} / \mathrm{Nafion} .{ }^{17}$ Recently, $\mathrm{Gao}^{18}$ fabricated an ultrathin polypyrrole-tetradecyl sulfonate filmmodified gold electrode for the simultaneous determination of DA and AA with high sensitivity and selectivity.

$\doteqdot$ To whom correspondence should be addressed.
In the present work, a covalently modified glassy carbon electrode with $\beta$-alanine monolayer has been fabricated via the electrooxidation of $\beta$-alanine to its analogous cation radicals to form a chemically stable covalent linkage between the nitrogen atom of the amine group and the edge plane sites at the carbon electrode surface. This electrode was applied to induce the voltammetric separation between DA and AA, which would make feasible the simultaneous determination of DA and AA in a mixture. The advantage was inherent in the fact that interfacial electron transfer can take place over a broad window of potentials, whereas electron cross exchange via redox mediators is limited by the redox potential of mediator and provides only a narrow useful potential window.

\section{Experimental}

\section{Apparatus}

All electrochemical experiments were performed with a $\mathrm{CHI}$ 832 electrochemical workstation (USA) in a conventional threeelectrode electrochemical cell using glassy carbon (3-mm diameter, BAS) as the working electrode, twisted platinum wire as the auxiliary electrode, and the saturated calomel electrode (SCE) as the reference electrode. The surface area of the GCE has been determined by Methylene Blue adsorption. ${ }^{19,20}$ An average value of $0.092 \mathrm{~cm}^{2}$ was found, which indicated that the surface area was about 1.3 times larger than its geometric area.

\section{Chemicals and solutions}

$\beta$-Alanine was purchased from Sigma. Dopamine hydrochloride was purchased from Fluka. Ascorbic acid and 
acetonitrile were obtained from Chemical Reagent Company of Shanghai (China). Acetonitrile was of analytical quality and was dried over $3 \AA$ molecular sieve before use; all other reagents were used as supplied, analytical grade. Solution of $\beta$ alanine was prepared in acetonitrile containing $0.1 \mathrm{~mol} / \mathrm{L}$ $\mathrm{NBu}_{4} \mathrm{BF}_{4}, \mathrm{DA}$ and $\mathrm{AA}$ were prepared with doubly distilled water immediately prior to use. PBS $0.1 \mathrm{~mol} / \mathrm{L}$ solutions at various $\mathrm{pH}$ values, prepared by mixing four stock solutions of $0.1 \mathrm{~mol} / \mathrm{L} \mathrm{H}_{3} \mathrm{PO}_{4}, \mathrm{KH}_{2} \mathrm{PO}_{4}, \mathrm{~K}_{2} \mathrm{HPO}_{4}$ and $\mathrm{K}_{3} \mathrm{PO}_{4}$, were used as supporting electrolytes for the determination of DA and AA.

\section{Preparation of the modified electrode}

The glassy carbon electrodes (GCEs) were prepared by polishing first with fine wet emery paper (grain size 4000) followed by 6.0 and $1.0 \mu \mathrm{m}$ alumina slurry on microcloth pads (Buehler, USA) to a mirror-like finish. The GCEs were sonicated in water for $15 \mathrm{~min}$ after each polishing step. After the initial polishing, GCEs were resurfaced using $1.0 \mu \mathrm{m}$ alumina slurry only. All GCEs were sonicated for $15 \mathrm{~min}$ in water, rinsed with water and ethanol, and dried with a stream of highly purified nitrogen immediately prior to use. The electrodes were then treated with cyclic scanning in the potential range of $0.50-1.80 \mathrm{~V}$ at $20 \mathrm{mV} / \mathrm{s}$ for five scans in 1.0 $\times 10^{-3} \mathrm{~mol} / \mathrm{L} \beta$-alanine (ACN, $0.1 \mathrm{~mol} / \mathrm{L} \mathrm{NBu}_{4} \mathrm{BF}_{4}$ ). After the electrode was rinsed with ethanol and water and sonicated for $15 \mathrm{~min}$ in $0.1 \mathrm{~mol} / \mathrm{L}$ PBS ( $\mathrm{pH} \mathrm{6.0)(this} \mathrm{process} \mathrm{was} \mathrm{used} \mathrm{to}$ remove any physisorbed, unreacted materials from the electrode surface), the $\beta$-alanine modified electrode (Ala/GCE) was ready for use. The Ala/GCE was stored in $0.1 \mathrm{~mol} / \mathrm{L}$ PBS (pH 6.0) at $4^{\circ} \mathrm{C}$

\section{Procedures}

All experiments were made at room temperature $\left(\mathrm{ca} .21^{\circ} \mathrm{C}\right)$. Differential pulse experiments employed a scan rate of $10 \mathrm{mV} / \mathrm{s}$, a pulse amplitude of $25 \mathrm{mV}$, a pulse rate of $0.5 \mathrm{~s}$ and a pulse width of $60 \mathrm{~ms}$. In all experiments, the solutions and the electrodes were kept motionless. The solutions were thoroughly deoxygenated by bubbling highly purified nitrogen and a nitrogen atmosphere was maintained over the solutions.

XPS was performed on an ESCALAB-MKII spectrometer (VG Co., UK) with Mo $\mathrm{K}_{\alpha} \mathrm{X}$-ray radiation as the $\mathrm{X}$-ray source for excitation. The data were obtained at room temperature; typically the operating pressure in the analysis chamber was below $10^{-9}$ Torr with an analyzer pass energy of $50 \mathrm{eV}$. The resolution was $0.2 \mathrm{eV}$. The elemental nitrogen-to-carbon ratio (N/C) can be used for assessing the extent of modifier coverage. Values for N/C were calculated by dividing the total number of counts under the $\mathrm{N}(1 \mathrm{~s})$ band by that under the $\mathrm{C}(1 \mathrm{~s})$ band and multiplying the results by 100 after accounting for the differences in sensitivity factors. ${ }^{21}$

\section{Results and Discussion}

Electrochemical modification of $\beta$-alanine at GCE surface

$\beta$-Alanine presents a single broad and irreversible oxidation peak at $1.20 \mathrm{~V}$ (Fig. 1(A)) on GCE in ACN containing 0.1 $\mathrm{mol} / \mathrm{L} \mathrm{NBu}_{4} \mathrm{BF}_{4}$. No cathodic peak can be observed on the reverse scan when the scan rate was increased up to $2.0 \mathrm{~V} / \mathrm{s}$, indicating that the species obtained after the first electron transfer undergoes a chemical reaction. The one-electron oxidation of the amino group turns it into its corresponding cation radical. ${ }^{22}$ These cation radicals form carbon-nitrogen linkages at the carbon electrode surface. ${ }^{23,24}$ The oxidation peak response decreased quickly with the successive scanning till the
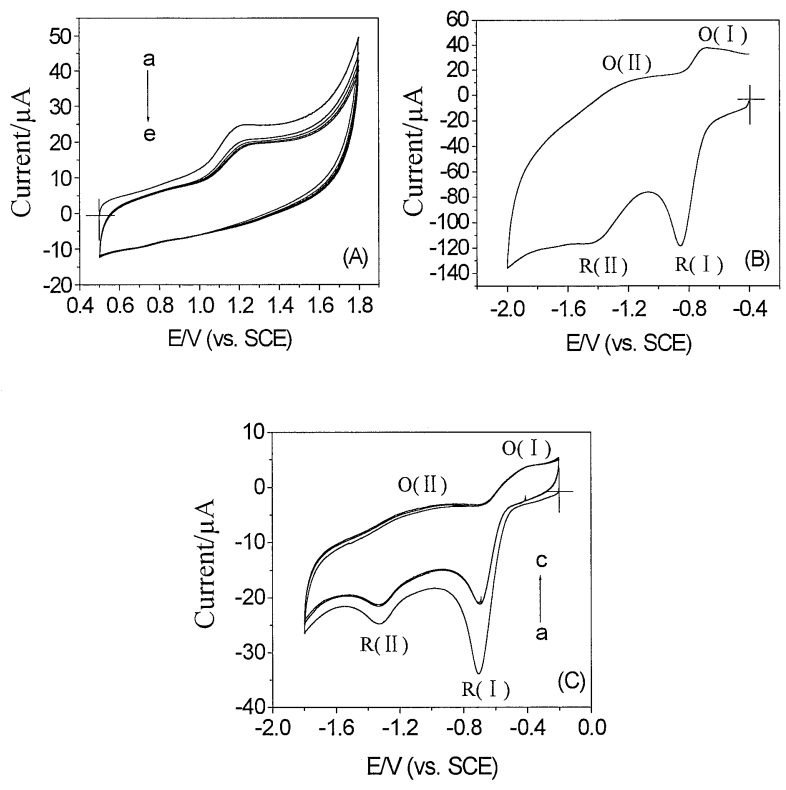

Fig. 1 Cyclic voltammograms of $\beta$-alanine. Solvent: ACN Electrode: glassy carbon. Supporting electrolyte: $0.1 \mathrm{~mol} / \mathrm{L}$ $\mathrm{NBu}_{4} \mathrm{BF}_{4}$. Scan rate: $20 \mathrm{mV} / \mathrm{s}$. (A) and (B): GCE in $\beta$-alanine solution $\left(1.0 \times 10^{-3} \mathrm{~mol} / \mathrm{L}\right) ;(\mathrm{C})$ : Ala/GCE in solution containing only $\mathrm{ACN}$ and $0.1 \mathrm{~mol} / \mathrm{L} \mathrm{NBu}_{4} \mathrm{BF}_{4}$. (a), (b), (c), (d), (e): the first, second, third, fourth and fifth cycles.

fifth cycle. This is attributed to the passivation of the electrode. Such passivation is related to the grafting of $\beta$-alanine on GCE surface. The modification process was almost finished after five cycles. Deinhammar ${ }^{25}$ reported the modification of GCE with amine-containing compounds, which suggests that diffusion rates as well as steric effects are the most significant factors affecting the immobilization of amine-containing compounds at GCE surfaces. As a primary amine, the electrochemical behavior of $\beta$-alanine is in line with the literature. ${ }^{25}$ Accordingly, we propose the EC modification process as in Scheme 1.

$$
\begin{aligned}
& { }_{\mathrm{GCE}} \lambda+\mathrm{NH}_{2}-\mathrm{CH}_{2}-\mathrm{CH}_{2}-\mathrm{COOH} \stackrel{-\mathrm{e}-}{\longrightarrow}{ }^{\mathrm{GCE}} \lambda{ }^{+}{ }^{+} \mathrm{NH}_{2}-\mathrm{CH}_{2}-\mathrm{CH}_{2}-\mathrm{COOH} \\
& \stackrel{-\mathrm{H}^{+}}{\longrightarrow} \mathrm{GCE} \lambda-\mathrm{NH}-\mathrm{CH}_{2}-\mathrm{CH}_{2}-\mathrm{COOH} \\
& \stackrel{\mathrm{NH}-\mathrm{CH}_{2}-\mathrm{CH}_{2}-\mathrm{COOH}}{ }
\end{aligned}
$$

Scheme 1

To verify that the electrooxidation of amine functionality is requisite for immobilization. XPS was used to follow the changes in the relative nitrogen content at GCE surface as a function of anodic voltage limit in a five-sweep CV experiment. Figure 2 shows the findings of the XPS characterization in the $\mathrm{N}(1 \mathrm{~s})$ region. Figure 2(a) is the result for a GCE immersed in solution with the applied voltage held at $0.00 \mathrm{~V}$ for $5 \mathrm{~min}$. Figures $2(\mathrm{~b}-\mathrm{d})$ are data for GCEs cycled between $0.00 \mathrm{~V}$ and different upper voltage limits: $0.65 \mathrm{~V}$ (Fig. 2(b)), $1.00 \mathrm{~V}$ (Fig. 2(c)), $1.60 \mathrm{~V}$ (Fig. 2(d)), and Fig. 2(e) is that for a freshly polished but untreated GCE for comparison. The XPS for a GCE immersed in solution at open circuit is effectively the same as in parts (a) and (e); only trace levels of nitrogen are 


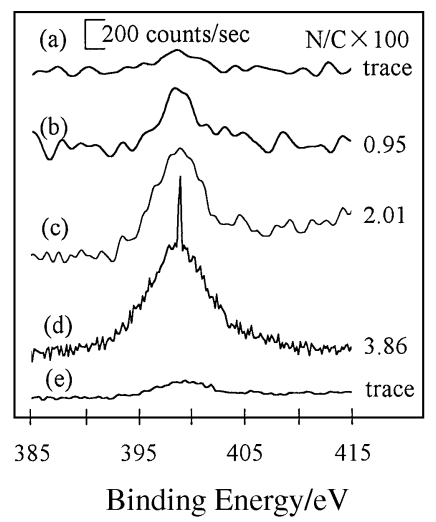

Fig. 2 XPS in the $\mathrm{N}(1 \mathrm{~s})$ region for freshly GCE immersed in $\beta$ alanine solution $\left(1.0 \times 10^{-3} \mathrm{~mol} / \mathrm{L}\right)$ and hold at $0.00 \mathrm{~V}$ for $5 \mathrm{~min}(\mathrm{a})$, or cycled for five scans at $20 \mathrm{mV} / \mathrm{s}$ between $0.00 \mathrm{~V}$ and $0.65 \mathrm{~V}$ (b), $1.00 \mathrm{~V}$ (c), and $1.60 \mathrm{~V}(\mathrm{~d})$. The spectrum in part (e) was obtained from a freshly polished GCE.

detected. In contrast, scanning to the upper limit of $0.65 \mathrm{~V}$ leads to the increase of nitrogen content $(\mathrm{N} / \mathrm{C}=0.95)$. Upon scanning to the more positive voltage limits, the nitrogen content increases further, reaching N/C of 2.01 at $1.00 \mathrm{~V}$ and 3.86 at $1.60 \mathrm{~V}$. These data show that oxidation of the amine functionality is requisite for immobilization at GCE surface. On the other hand, the position of peak maximum at $398.60 \mathrm{eV}$, which is consistent with the formation of carbon-nitrogen bond between the amine cation radical and an aromatic moiety of GCE surface, also verify the immobilization of $\beta$-alanine on GCE.

Furthermore, the stability of the immobilized $\beta$-alanine layer also supported the formation of a covalent linkage. For instance, after the GCEs were treated according to the experiment, the electrodes were sonicated for $15 \mathrm{~min}$ in a variety of solutions, including water, ethanol, and pH 6.0 PBS, and then thermo-desorbed in high vacuum $\left(10^{-9}\right.$ Torr $)$ for 40 min at $110^{\circ} \mathrm{C}$. In all cases, the XPS data were not observably different from that in Fig. 2(d).

To further investigate the structure of the modification layer, we studied the surface density of amines on GCE using CV. Oxidation of the amino group with a carbon electrode should allow the molecules to be bonded to the carbon. Once the molecule was bonded, it should be possible to observe its reduction. From the area of the reduction peak of the voltammogram, one can deduce the number of molecules which were bonded. The oxidation and reduction voltammograms of $\beta$-alanine are shown in Figs. 1(A) and 1(B). As can be seen, the oxidation of $\beta$-alanine was monoelectron and irreversible, while the reduction presents two pairs of reversible redox waves $\left(\mathrm{R}(\mathrm{I}) / \mathrm{O}(\mathrm{I})\right.$ and $\mathrm{R}(\mathrm{II}) / \mathrm{O}(\mathrm{II})$ with $\Delta E_{\mathrm{p}}$ of 0.14 and $0.13 \mathrm{~V}$, respectively. The cathodic wave $\mathrm{R}(\mathrm{I})$ at $-0.87 \mathrm{~V}$ and the anodic wave $\mathrm{O}(\mathrm{I})$ at $-0.73 \mathrm{~V}$ were attributed to the reduction and reoxidation of carboxylic functionalities in the molecules of $\beta$ alanine bonded on the electrode surface with a four-electron process. ${ }^{26}$ The other pair of redox waves $\mathrm{R}(\mathrm{II}) / \mathrm{O}$ (II) observed at -1.40 and $-1.27 \mathrm{~V}$, respectively, corresponds to the reduction and reoxidation of amine group with a monoelectron process. After $\beta$-alanine was bonded to the electrode, the electrode was carefully rinsed in an ultrasonic cleaner and transferred to ACN solution $\left(0.1 \mathrm{~mol} / \mathrm{L} \mathrm{NBu}_{4} \mathrm{BF}_{4}\right)$. The reduction voltammograms of Fig. 1(C) were then observed. Most of the reversibility was lost and upon successive scans the voltammograms were slowly
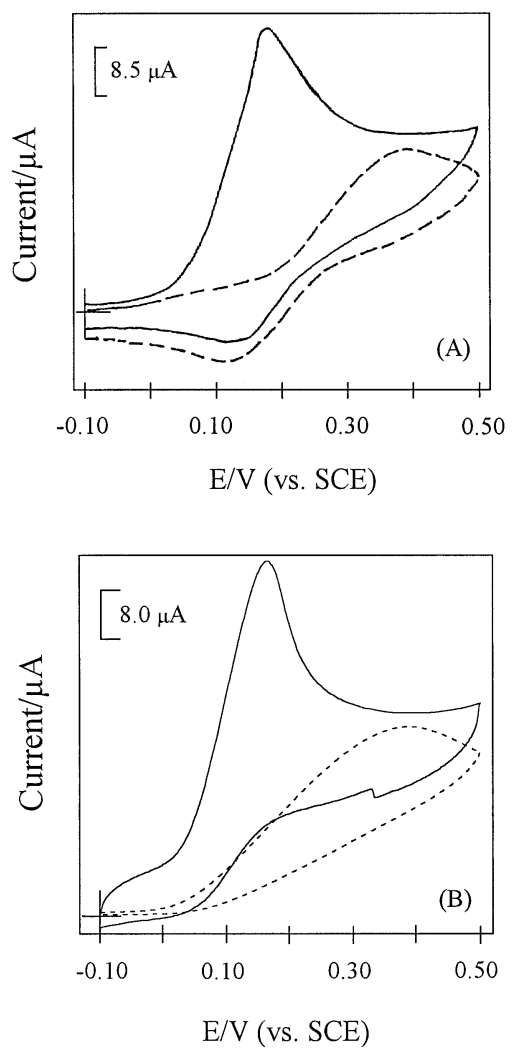

Fig. 3 Cyclic voltammograms of $1.0 \times 10^{-4} \mathrm{~mol} / \mathrm{L} \mathrm{DA}(\mathrm{A})$ and 5.0 $\times 10^{-4} \mathrm{~mol} / \mathrm{L} \mathrm{AA} \mathrm{(B)} \mathrm{at} \mathrm{GCE} \mathrm{(dashed} \mathrm{line)} \mathrm{and} \mathrm{Ala/GCE} \mathrm{(solid} \mathrm{line)}$ in $0.1 \mathrm{~mol} / \mathrm{L} \mathrm{PBS}(\mathrm{pH}=6.0)$. Scan rate: $50 \mathrm{mV} / \mathrm{s}$.

drawn out. The loss of the reversibility and the stretching the voltammogram may be ascribed to the protonation of the radical anion by residual water. From the area of the first voltammogram, the number of molecules which had undergone a monoelectron reduction can be deduced. Knowing the surface area of the electrode, one can calculate a concentration of $1.68 \times$ $10^{-10} \mathrm{~mol} / \mathrm{cm}^{2}$, which is in agreement with the values of about $10^{-10} \mathrm{~mol} / \mathrm{cm}^{2}$ as the monolayer surface coverage. ${ }^{27}$ These results showed that approximately one monolayer of $\beta$-alanine was bonded to the carbon surface.

\section{Electrochemical behavior of $D A$ and $A A$ at Ala/GCE}

From the cyclic voltammograms of Ala/GCE in $0.1 \mathrm{~mol} / \mathrm{L}$ PBS ( $\mathrm{pH}$ 6.0), we found no redox peak which appeared between 0.00 and $0.80 \mathrm{~V}$. Thus, this modified electrode provided a broad potential window to investigate the voltammetric behaviors of DA and AA

Figures 3(A) and (B) show the cyclic voltammograms of DA and $\mathrm{AA}$ at GCE and Ala/GCE, respectively. As can be seen, DA shows a sluggish and much smaller CV peak response with a $\Delta E_{\mathrm{p}}$ of $0.27 \mathrm{~V}$ at GCE, while Ala/GCE leads to an obvious increase of oxidation current and decrease of reduction current with a more reversible behavior $\left(\Delta E_{\mathrm{p}}=0.054 \mathrm{~V}\right)$. Figure 3(B) shows that the oxidation of AA was broad, nonreproducible at $0.38 \mathrm{~V}$ with a $E_{\mathrm{p}}-E_{\mathrm{p} / 2}$ of $0.19 \mathrm{~V}$ at GCE. In contrast, the oxidation current increased greatly and the peak potential shifted negatively to $0.16 \mathrm{~V}$ with a $E_{\mathrm{p}}-E_{\mathrm{p} / 2}$ of $0.068 \mathrm{~V}$ at Ala/GCE. The changes of the peak currents and the decreases in the anodic overpotentials of about $0.20 \mathrm{~V}$ for DA and $0.23 \mathrm{~V}$ for AA indicate the strong electrocatalytic function of Ala/GCE to DA and AA. The shifts in the overpotentials were due to a 


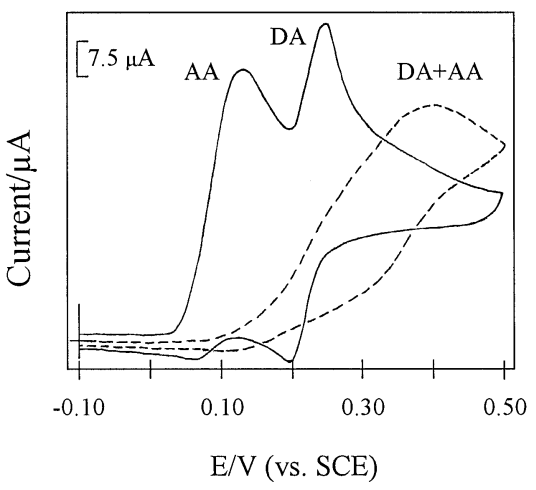

Fig. 4 Cyclic voltammograms of the mixture of DA $\left(1.0 \times 10^{-4}\right.$ $\mathrm{mol} / \mathrm{L})$ and $\mathrm{AA}\left(5.0 \times 10^{-4} \mathrm{~mol} / \mathrm{L}\right)$ at GCE (dashed line) and $\mathrm{Ala} / \mathrm{GCE}$ (solid line) in $0.1 \mathrm{~mol} / \mathrm{L} \mathrm{PBS}(\mathrm{pH}=6.0)$. Scan rate: $50 \mathrm{mV} / \mathrm{s}$.
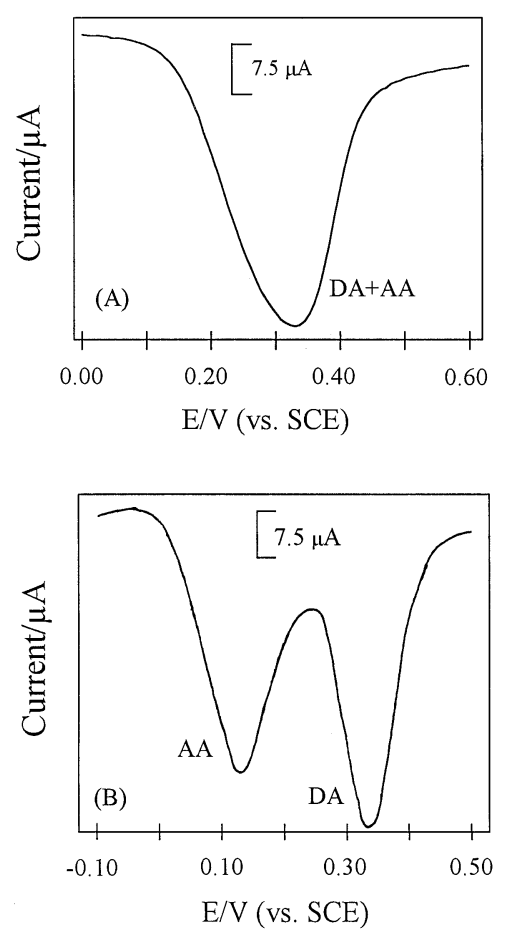

Fig. 5 Differential pulse voltammograms of the mixture of DA (1.0 $\left.\times 10^{-4} \mathrm{~mol} / \mathrm{L}\right)$ and AA $\left(5.0 \times 10^{-4} \mathrm{~mol} / \mathrm{L}\right)$ at GCE (A) and Ala/GCE (B) in $0.1 \mathrm{~mol} / \mathrm{L}$ PBS $(\mathrm{pH}=6.0)$. Scan rate: $50 \mathrm{mV} / \mathrm{s}$.

kinetics effect; thus substantial increases in the rate of electron transfer from DA and AA were observed, which was attributed to the improvements in the reversibility of the electron transfer processes. ${ }^{28}$

Further investigation was made into the transport characteristics of DA and AA in the modified electrodes. The linear scan voltammetric current responses for DA and AA at $\mathrm{Ala} / \mathrm{GCE}$ were found to be linear with the square root of scan rate in the ranges of $20-200$ and $20-280 \mathrm{mV} / \mathrm{s}$, respectively. It indicates that the electrode reactions are controlled by diffusion processes. More types of evidence for the diffusion behaviors were demonstrated by the following experiments. When Ala/GCE was switched to $0.1 \mathrm{~mol} / \mathrm{L} \mathrm{PBS} \mathrm{(pH} \mathrm{6.0)} \mathrm{after}$ being used in DA or AA, there were no peak signals at all.

When DA and AA coexisted in the same sample, a rather broad anodic peak was observed at $0.40 \mathrm{~V}$ using CV (Fig. 4,
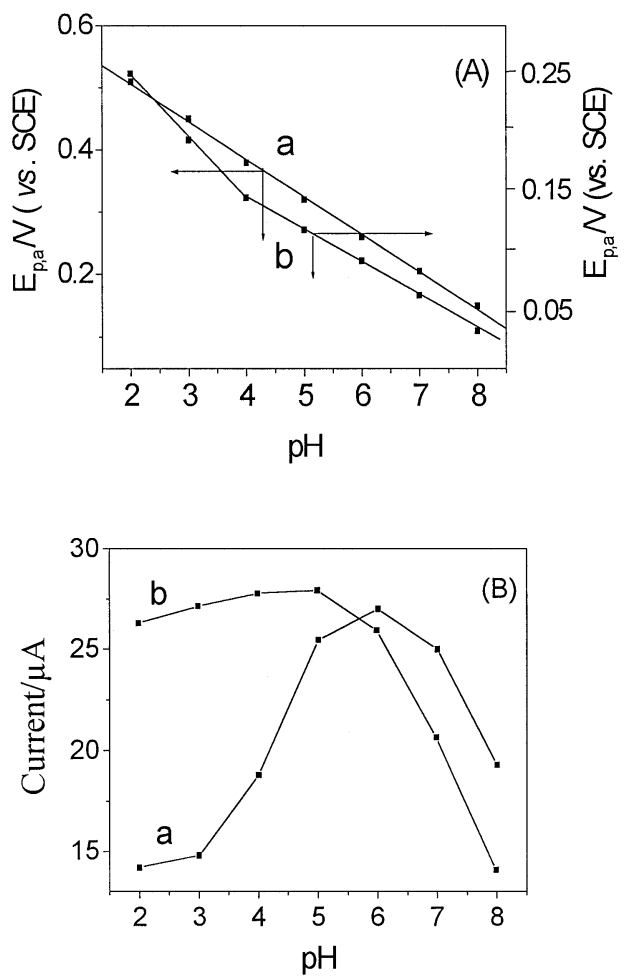

Fig. 6 Dependence of peak potential (A) and of peak current (B) of $1.0 \times 10^{-4} \mathrm{~mol} / \mathrm{L} \mathrm{DA}$ (a) and $5.0 \times 10^{-4} \mathrm{~mol} / \mathrm{L} \mathrm{AA}$ (b) on solution $\mathrm{pH}$ at Ala/GCE in $\mathrm{pH}$ 6.0 PBS. Scan rate: $50 \mathrm{mV} / \mathrm{s}$.

dashed line) and at $0.33 \mathrm{~V}$ using DPV (Fig. 5A) at GCE, and the peak potentials for DA and AA were indistinguishable. Thus it is impossible to deduce any conclusive information from the broad voltammetric peaks. Ala/GCE resolved the overlapping voltammetric response into two well-defined peaks at 0.25 and $0.13 \mathrm{~V}$ in CV (Fig. 4, solid line) and 0.34 and $0.13 \mathrm{~V}$ in DPV (Fig. 5B), corresponding to the oxidation of DA and AA, respectively. The separations between the two peak potentials were about $0.12 \mathrm{~V}$ in $\mathrm{CV}$ and $0.21 \mathrm{~V}$ in DPV, which were large enough for the simultaneous determination of DA and AA in a mixture.

\section{Analytical characterization}

First, the effects of $\mathrm{pH}$ on the electrode signal and oxidation potential were investigated using CV. Results are shown in Fig. 6. As can be seen, the peak potential for DA shows a linear variation with $\mathrm{pH}$ and is shifted to a more negative potential with a slope of $57 \pm 2 \mathrm{mV} / \mathrm{pH}$ (Fig. 6(A), curve (a)), which is very close to the theoretical value of $59 \mathrm{mV} / \mathrm{pH}$ for the $2 \mathrm{e}^{-} / 2 \mathrm{H}^{+}$ process. Curve (b) shows the trends of peak potential for AA with increasing $\mathrm{pH}$. As can be seen, the slope of the $E_{\mathrm{p}, \mathrm{a}} v s . \mathrm{pH}$ is about $53 \pm 2 \mathrm{mV} / \mathrm{pH}$ between $\mathrm{pH} 2.0-4.0$, indicating that a $1 \mathrm{e}^{-} / 1 \mathrm{H}^{+}$reaction was involved in the oxidation process, whereas at higher $\mathrm{pH}$ values the slope decreased to about $34 \pm 2 \mathrm{mV} / \mathrm{pH}$, suggesting a $2 \mathrm{e}^{-} / 1 \mathrm{H}^{+}$transfer process. Consequently, the overall electrode reaction can be classified as an electrochemical reaction followed by a chemical reaction process, as previously reported. ${ }^{29-31}$ Figure 6(B) shows the variation of peak current with $\mathrm{pH}$. As can be seen, the peak current of DA reached a maximum at $\mathrm{pH} 6.0$, and that of $\mathrm{AA}$ increased slightly from $\mathrm{pH} 2.0$ to 5.0 , then decreased quickly with increasing $\mathrm{pH}$. The peak current of AA in acid solution was higher than that in basic solution, which was due to the 
Table 1 Determination of DA and AA in mixtures

\begin{tabular}{lcccc}
\hline No. & $\begin{array}{c}\text { DA content/ } \\
10^{-4} \mathrm{~mol} \mathrm{~L}^{-1}\end{array}$ & $\begin{array}{c}\text { AA content/ } \\
10^{-3} \mathrm{~mol} \mathrm{~L}\end{array}$ & $\begin{array}{c}\text { DA found/ } \\
10^{-4} \mathrm{~mol} \mathrm{~L}^{-1}\end{array}$ & $\begin{array}{c}\text { AA found/ } \\
10^{-3} \mathrm{~mol} \mathrm{~L}^{-1}\end{array}$ \\
\hline 1 & 1.06 & 2.50 & 1.02 & 2.41 \\
2 & 1.06 & 2.50 & 1.05 & 2.37 \\
3 & 1.06 & 2.50 & 0.94 & 2.34 \\
4 & 1.06 & 2.50 & 0.96 & 2.40 \\
5 & 1.06 & 2.50 & 0.98 & 2.44 \\
Average & & 0.99 & 2.39 \\
Relative standard derivation & $6.6 \%$ & $4.3 \%$ \\
\hline
\end{tabular}

instability of AA in basic solution. ${ }^{32}$ Considering the physiological $\mathrm{pH}$ (7.4) and sensitivity, we selected the solution $\mathrm{pH}$ as 6.0.

Under optimum conditions, in the differential pulse mode the catalytic peak current was linearly related to DA concentration over the range of $4.0 \times 10^{-6}-5.0 \times 10^{-4} \mathrm{~mol} / \mathrm{L}$ in the presence of $5 \times 10^{-5} \mathrm{~mol} / \mathrm{L}$ AA. For the regression plot of $i_{\mathrm{p}, \mathrm{a}} v s$. DA concentration, the slope $=47.5 \mathrm{nA} / \mu \mathrm{M}, y$-intecept $=54.8 \mathrm{nA}$ and correlation $\left(r^{2}\right)=0.997$. The detection limit $(3 \sigma)$ was $2.4 \times$ $10^{-6} \mathrm{~mol} / \mathrm{L}$. At the same time, when DA was $5 \times 10^{-4} \mathrm{~mol} / \mathrm{L}$, the calibration plot of AA was linear in the range $2.0 \times 10^{-5}$ $6.0 \times 10^{-3} \mathrm{~mol} / \mathrm{L}$ with the slope $(\mathrm{nA} / \mu \mathrm{M})$, intercept $(\mathrm{nA})$ and correlation $\left(r^{2}\right)$ of $42.4,57.4$ and 0.995 , respectively. The detection limit was $1.2 \times 10^{-5} \mathrm{~mol} / \mathrm{L}$.

As an example for the analytical performance of the modified electrode, some mixtures of DA and AA were analyzed. The dopamine hydrochloride injection (DHI) solution $(10 \mathrm{mg}$ DA per $\mathrm{mL}, 2 \mathrm{~mL}$ per injection) was diluted to $10 \mathrm{~mL}$ with water, $100 \mu \mathrm{L}$ of DHI solution and $1.0 \mathrm{~mL}$ AA standard solution $(0.025 \mathrm{~mol} / \mathrm{L})$ were added to a series of $10 \mathrm{~mL}$ measuring flasks and made up to volume with pH 6.0 PBS. An aliquot of $5.0 \mathrm{~mL}$ of the solution was piped into the electrochemical cell, and then the concentrations of DA and AA were determined by calibration methods. Results are shown in Table 1. The good agreement with the standard content is a promising feature for the applicability of the modified electrode for the simultaneous determination of DA and AA in samples.

\section{Electrode stability}

Since the procedure of electrode preparation is easy and rapid, it is not so important for the electrode to be stable for a prolonged time. However, we checked its long-term stability by measuring the response from day to day during storage in PBS $(\mathrm{pH} 6.0)$ at $4^{\circ} \mathrm{C}$. During the first two days, the current response had no apparent decrease and in the next five days the current response decreased about $12 \%$ of its initial response; it decreased $25 \%$ for one month.

\section{Conclusions}

This study has demonstrated that the Ala/GCE not only exhibited strong electrocatalytic functions toward the oxidation of DA and AA, but also resolved the overlapping anodic peak of DA and AA into two well-defined peaks. Thus DA and AA contents can be detected simultaneously in a mixture. Importantly, this modified process simplifies the fabrication of modified electrode, a process that often involves a series of pretreatment, activation, and function steps. The modified electrodes showed good sensitivity, selectivity and stability. Although realization of these selectivity and sensitivity enhancements in neurochemical studies would require electrode miniaturization and further studies, preliminary experiments are promising. The success in detecting DA and AA simultaneously in a mixture implies that this approach can be applied to in vivo studies.

\section{References}

1. R. N. Adams, Anal. Chem., 1976, 48, 1126A.

2. J. A. Stamford and J. B, Justice, Anal. Chem., 1996, 69, 359A.

3. R. D. O'Neill, Analyst, 1994, 119, 767.

4. Z. Gao, K. S. Siow, A. Ng, and Y. Zhang, Anal. Chim. Acta, 1997, 343, 49.

5. G. A. Gerhardt, A. F. Oke, F. Nagy, B. Moghaddam, and R. N. Adams, Brain Res., 1984, 290, 390.

6. J. Wang and M.-S. Lin, Electroanalysis, 1990, 2, 861.

7. J.-M. Zen, Y.-J. Chen, C. T. Hsu, and Y. S. Ting, Electroanalysis, 1997, 9, 1009.

8. (a) C. D. Blaha and R. F. Lane, Brain Res. Bull., 1983, 10, 861.

(b) M. B. Gelbert and D. J. Curran, Anal. Chem., 1986, 58, 1028.

(c) G. E. Glynn and B. K. Yamamoto, Brain Res., 1989 , $481,235$.

9. F. Malem and D. Manldler, Anal. Chem., 1993, 65, 37.

10. C. Aleksander and M. Grzegorz, Anal. Chem., 1999, 71, 1055.

11. W. M. A. Damien, Anal. Commun., 1997, 34, 241.

12. A. J. Downard, A. D. Roddick, and A. M. Bond, Anal. Chim. Acta, 1995, 317, 303.

13. J.-M. Zen and P.-J. Chen, Anal. Chem., 1997, 69, 5087.

14. K. Pihel, Q. D. Walker, and R. M. Wightman, Anal. Chem., 1996, 68, 2084.

15. X. Zhang, B. Ogorevc, G. Tavcar, and I. G. Svegl, Analyst, 1996, $121,1817$.

16. A.-M. Yu, D.-M. Sun, and H.-Y. Chen, Anal. Lett., 1997, $30,1643$.

17. H. Ju, J. Ni, Y. Gong, H. Chen, and D. Leech, Anal. Lett., 1999, 32, 2951.

18. Z. Gao and H. Huang, Chem. Commun., 1998, 2107.

19. L. Cheng, J. Liu, and S. Dong, Anal. Chim. Acta, 2000, $417,133$.

20. E. Laviron, Bull. Soc. Chim. Fr., 1967, 3717.

21. J. H. Scofield, J. Electron Spectrosc. Relat. Phenom., 1976, $8,129$.

22. C. K. Mann, Anal. Chem., 1964, 36, 2424.

23. B. Barbier, J. Pinson, G. Desarmot, and M. Sanchez, J. Electrochem. Soc., 1990, 137, 1757.

24. L. Zhang and X. Lin, Analyst, 2001, 126, 367.

25. R. S. Deinhammer, H. James W. A. Mankit, and M. D. Porter, Langmuir, 1994, 10, 1306.

26. H. M. Wu, R. Oliver, R. N. Jattrezic, P. Clechet, A. Nyamsi, and C. Martelet, Electrochim. Acta, 1994, 39, 331.

27. Q. Cheng and A. Brajter-Toth, Anal. Chem., 1996, 68, 4180.

28. J. Osteryoung and J. J. O'Dea, “Electroanalytical Chemistry", ed. A. J. Bard, 1988, Vol. 14, Marcel Dekker, New York.

29. P. Karabinas and D. Jannakoudakis, J. Electroanal. Chem., 1984, 160, 159.

30. I. F. Hu and T. Kuwana, Anal. Chem., 1986, 58, 3235.

31. M. Rueda, A. Aldaz, and F. Sanchez-Burgos, Electrochim. Acta, 1978, 23, 419.

32. Z. Gao and A. Ivaska, Anal. Chim. Acta, 1993, 284, 393. 